\title{
A Study on Myside Bias and the Iranian EFL Students
}

\author{
Atiyeh Kamyabi Gol \\ Department of Linguistics, Faculty of Letters and Humanities, Ferdowsi University of Mashhad, Mashhad, Iran
}

\begin{abstract}
As Leki and Carson (1994) emphasize: "ability to write well is necessary both to achieve academic success and to demonstrate that achievement" (p. 83). However, how the information is presented in a piece of writing is also important. Myside bias is mainly concerned with objectivity in argumentative writing. It is generally believed that by including counterarguments, the overall coherence of the writing will improve. With the growing number of Iranian students studying overseas, it is necessary to see whether these students' argumentative essays pay attention to both sides of an argument. 80 Iranian higher intermediate EFL Students were asked to write two argumentative essays. To further probe into participants' perception, an interview was held with 30 participants. Whether the participants' gender and age played a role in the presence of myside bias was also considered. The results revealed that $55 \%$ of the participants used myside bias in their English essays, but on $37.5 \%$ could be accused of myside bias in their Persian essays.
\end{abstract}

Index Terms — contrastive rhetoric, English argumentative writing, myside bias, Persian argumentative writing

\section{INTRODUCTION}

Effective written English is an essential tool for any academic and professional career (Liu \& You, 2008). The concept of writing has a very rich history dating back in time. Writing began in ancient Greece and has always received a great deal of attention from scholars of all time (Villasenor, 2003). As Wolfe, Britt and Butler (2009) emphasize, "the ability to comprehend and construct written arguments is an important skill for academic learning as well as for pursuits outside of school" (p. 183).

In Iran, English is considered a foreign language which is taught from junior high school onward. Learning English as a foreign language has become very popular during the past years. The increased number of English language institutes all over Iran along with the parents' elevated interest in enrolling their children in extra curricular English classes can be evidence to support this claim. Vaezi (2009) believes the main causes for this popularity are "the growth of international relations of Iran with other nations and the extended interest towards today's growing technology and science throughout the world" (p. 82). Vaezi (2009) and Sadighi and Maghsudi (2000) found Iranian students to be highly motivated in learning English. This was the case in both English major and non English major students studying at various universities in Iran.

Myside bias generally refers to a phenomenon where a writer only pays attention to his/her own point of view in an argumentative essay and does not include references to the other side of the argument. The main danger in the presence of myside bias in an argumentative essay is in producing texts which are no longer objective and are therefore biased towards one side of an argument. It is believed that myside bias undermines the coherence of the writing.

Therefore, it was important to see whether the Iranian EFL students in this study paid attention to objectivity while writing or whether they only focused on proving their own point of views in the argumentative essays they wrote. It was also important to check whether the results would be different for the students' native language essays as compared with their English ones. The 80 argumentative essays were evaluated by two bilingual (Persian/English) raters to insure interrater reliability (0.90). The idea of myside bias was initially checked in the written argumentative essays and also triangulated in the questionnaire items and also in the interviews with the same participants. The purpose of the present investigation was to examine the presence of myside bias in the Persian and English argumentative essays of 40 Higherintermediate Iranian EFL students and also to test the association between gender/age and the presence of myside bias.

\section{THEORETICAL BACKGROUND}

\section{A. Myside Bias}

Myside bias was first introduced by Perkins and his colleagues in 1985. This phenomenon has been the topic of research for well over 20 years. Myside Bias can be generally defined as "the tendency to evaluate evidence, generate evidence, and test hypotheses in a manner biased toward one's own opinions" (Macpherson \& Stanovich, 2007, p. 115). Wolfe and Britt (2008) define the Myside bias in a more restricted manner and they believe that myside bias in argumentation is "the failure to include any references to other-side arguments or positions in written essays" (p. 3).

In a study focused on abortion conducted by Baron (1995), it was realized that the participants favored those arguments that were on one side over those that presented both sides which showed the presence of myside bias. In 
searching for the reason of such findings Baron suggests that "people's standards - their beliefs about the nature of good thinking - affect the conduct of their own thinking" (p.228). Of course, it should be mentioned that one possibility for such results might have been the controversial idea of abortion due to its ethical and religious backgrounds.

Nussbaum and Kardash (2005) studied the effect of instruction manipulation on an essay writing task. They divided the students into two groups, and in one group they changed the neutral argumentative topic to the following: 'discuss two or three reasons why others might disagree with you and why those reasons are wrong' and they found out that this change generated more counterclaims than in the control group with a neutral topic. This shows that myside instruction on a writing task can stimulate more counterarguments in students.

In 2007, Stanovich and West studied over 1400 university students. They conducted two experiments on these participants and compared the participants' intelligence and the presence of myside bias; their results showed no correlation between intelligence and myside bias. On the results of the present research, Stanovich and West (2007) report that "In the two experiments reported here we found very little evidence that individuals higher in cognitive ability were better able to avoid myside bias" (p. 239).

In 2005, Wolfe and Britt (cited in Wolfe and Britt, 2008) analyzed 35 published essays including 13 longer essays from the Hookie Awards, and 22 editorials and Opposing Opinion pieces from USA Today; after a content analysis they came to conclude that $93 \%$ of the Hookie Awards essays, 100\% of the USA Today editorials, and 70\% of the USA Opposing Opinion pieces included other side information which shows the importance of paying attention to the other side of the arguments.

In 2008, Wolfe and Britt found that half of the undergraduates excluded the other side information from their arguments. Therefore, they gave a group of undergraduates a booklet on the importance of including both sides of an argument, and later they still found that $33 \%$ of the students still only paid attention to their idea on the argument.

Wolfe, Britt and Butler (2009) sum up their findings related to their experimental work on myside bias in 2008. They outline the various reasons why myside bias occurs. They write:

First was a failure to fully evoke an argumentation schema that encourages participants to consider both pro side and con side information. Second, some participants read both pro and con side arguments but "mined" them only for information on their side of an issue. Finally, some participants provided evidence of a fact-based argumentation schema, a tendency to view argumentation as a simple matter of arraying facts (p. 188).

In their study in 2009, Wolfe, Britt and Butler concentrated on reducing myside bias in students' argumentative essays in order to improve the quality of the essays. With this aim, they divided their 60 American students into two groups and asked them to write an argumentative essay. In the tutorial class, they taught some pointers in order to help the students' argumentative essay writing. Then they asked the students to write another argumentative essay and after analysis they found that while only $60 \%$ of the control group participants made a precise claim, $90 \%$ of the members in the tutorial class made the precise claims. This showed the effect of the tutorial session and awareness raising among students regarding argumentative essay writing.

\section{B. Argumentative Writing}

In recent years, a great deal of attention is being concentrated on argumentative writing and this has brought with it research in this area. In the past, most contrastive rhetoric studies consisted of expository essays, but recently, the focus of attention is being diverted to other genres such as argumentative and persuasive essays (Connor, 1996). Rozakis (2000) defines argumentation as a type of writing which:

Appeals specifically to reason. When you argue a point in writing, you analyze a subject, topic, or issue in order to persuade your readers to think or act a certain way (p.24-25).

As for the differences between various cultures regarding argumentative writing, Oliver (1971) and Eemeren and Houtlosser (2005) assert that the aim of argumentation in the Western culture is mainly to influence the audience and also to try to get the audience to agree with the writer's point of view. This has been mentioned by Mason and Otte (1994) when they say: "rational argument is our chief way of winning allies and converts to our way of thinking" (p. 179). In contrast to the Western method, the Asian writers aim at getting their ideas accepted by the reader and they do not go beyond this level so as to get the audience to agree with them. So, the purpose is to enlighten the audience and not to go beyond this level and aim at convincing them.

Some shocking results from past research on argumentation and argumentative writing tend to stand out; for example, Wolfe, Britt, and Butler (2009) announce that according to the National Assessment of Educational Progress in U.S.A., only $15 \%$ of twelfth graders are adequately prepared to write arguments. This would mean that the other $85 \%$ of these students lack the required skill to perform such a task.

In another study, conducted in two separate phases, initially Oi (1984) found out that English argumentative writing which is linear generally follows a general to specific pattern while the Japanese argumentative pattern seems to be the exact opposite of moving from specific to general. From this finding, Oi suggested using a tool which she called the inner argumentative analysis in order to improve the Japanese argumentative style of writing. In her method, the students would first learn to analyze argumentative texts and find out which ones were "for" and which were "neutral" and which "against" the presented argument. In the second phase of the study done by both Oi and Kamimura (1995), 87 students were divided into two groups and they were given 40 minutes to write an argumentative essay. In the next session, one group was taught how to use Oi's tool on two passages and also examined their own essays from the first session. In the 
final session, all the students were asked to write another argumentative essay. The researchers then compared the two argumentative essays written by each student and found out that the instructions given to the group of students helped them to improve their argumentative essay writing.

Although argumentative style of writing is very popular in English it is not, however, a part of the writing courses offered to students at schools in many languages including Russian, Japanese, Korean, Chinese, Thai, Hindi, and Arabic (Petric, 2005; Hinds, 1990; Kachru, 1999; Liebman, 1992). A possible reason for not including argumentative style of writing in Russian is that they believe this style is related to journalism and not academic writing. After a great deal of research, Saneh (2009) also admits that there is "very scant literature" (p. 179) when it comes to the structure of argumentation in Persian language.

In her study, Saneh (2009) interviewed some university professors in order to find the root of the problem in Iranian students' argumentative writing. One of the bilingual (Persian/English) professors mentioned that the Iranian students failed to incorporate rebuttals in their argumentative writings and he believed the reason for this was the attitude differences between the Iranian and American society and educational context:

You know, one of the flaws of the arguments of my Iranian students and I think the logic in Persian language is that you never give the light of day to the person you oppose. You even falsify them and you think you're in the right in doing so. I keep telling my students that they need to tone down the claims they are making and the position they're offering through appropriate hedging, through speaking tentatively rather than deterministically. But their attitude is different. You see that they [Iranian students] come from a background of accepting rather than questioning. (p. 134).

According to Givi, Hakemi, Shokri, and Tabatabaee (2006), one important feature to keep in mind in Persian argumentative writing is objectivity. They believe this is one of the pointers that most students do not take into consideration when writing. This objectivity is a topic that has not received its due attention in the Iranian EFL setting.

Regarding the above mentioned points, the present study aims to answer the following questions:

1. Does the myside bias exist in the Persian argumentative writings of Iranian EFL students?

2. Does the myside bias exist in the English argumentative writings of Iranian EFL students?

3. Does gender play any role in the presence of myside bias in the Higher-intermediate Iranian EFL students' English and Persian argumentative writing?

4. Does age play any role in the presence of myside bias in the Higher-intermediate Iranian EFL students' English and Persian argumentative writing?

\section{MATERIAL AND METHODS}

To testify the truth or falsity of the research questions, the researcher initially decided to collect and analyze data. In pursuing an answer to the first two research questions, the researcher turned to Wolfe, and Britt's (2008) definition of the Myside bias in which they believe myside bias in argumentation is "the failure to include any references to other-side arguments or positions in written essays" (p. 3). The answers to the third and fourth research questions were checked in SPSS and the data provided from the demographics of the questionnaire.

\section{A. Participants}

80 Higher-intermediate Iranian EFL students were asked to fill out a demographic form (See Appendix 1) and write two argumentative essays. These students were chosen from a well known college in Mashhad, Iran. The 80 students who participated in the main section of the present study were all university students. They were majoring in foreign languages, engineering, basic sciences. Their ages ranged from 20 to 40, (Mean= 27, SD= 5.124). Overall, 33 males (Mean= 26.85, SD= 4.079) and 47 females (Mean=26.81, $\mathrm{SD}=4.962)$ took part in this section. All the participants had studied English for at least 3 years in College. This was necessary in order to make sure the participants have a good command of English in order to make good judgments regarding their English writing problems. These students were at a Higher-intermediate level of proficiency in English based on a TOEFL (Test Of English as a Foreign Language) exam. The single stage sampling of participants was conducted based on these students' availability as "potential respondents in the population" (Creswell, 2009; p. 148).

After signing the consent form and filling out the demographic section the 80 students composed two essays. This made an overall 160 essays written by the participants.

\section{B. Argumentative Writing Task}

According to Kim (2008), most cross-cultural studies based on rhetorical patterns suffer from 2 weaknesses. First, they only take into account the English texts that the ESL/EFL student has written with the belief that "the ESL composition s would reflect the rhetorical patterns of the students' first language" (p.1). Second, Kim (2008) believes that when the ESL/EFL students are asked to write only in English, they might be "primed by English culture and may try to adopt English rhetorical patterns rather than follow the rhetorical styles preferred in their native culture" (p. 2). In order to get a better perspective when studying the rhetoric of any specific culture, it is necessary to "investigate the texts written in the speakers' native language in order to determine whether the rhetorical pattern is transferred from the native language" (p.3). 
In order to avoid translation from one language to another, participants were not informed in the beginning that they would be writing about the same topic in both Persian and English, and the second essay writing task was given one week after the first task was introduced. Writing was done outside the class to ensure sufficient time for writing. All the essays were typed in order to facilitate text analysis and avoid illegible handwriting. All errors remained unchanged in the typed texts.

A total of 80 Iranian Higher-intermediate EFL Students were asked to write two 300-350 word Persian and English argumentative essays. The students were instructed to write an essay arguing for or against the idea of establishing coeducational elementary schools in Iran. This was translated into Persian as "ايجاد دبستان هاى مختلط در ايران بايد تثويق كردد "En A week later, the same instructions were given to the students but this time round they were asked to write an English essay with the same topic. Since the researcher wanted to check whether the students would transfer Persian structures and expressions to their English essays, the Persian essay was appointed to the participants first [Reid (1984); Saneh (2009)].This topic was chosen because it is a controversial issue that has been debated in Iran.

The main reason for choosing this number of words for the essays was that the students' writing tasks generally ask for 300-350 words and so the students are acquainted with this for their writing activities. Also, since the argumentative essays were going to be a part of the students' class writing activity, the researcher needed to follow the classes' normal procedures. There was no time restriction as many scholars (Kobayashi \& Rinnert, 2008; Zia Houseini \& Derakhshan, 2006; Raimes, 1983) believe time restriction can hinder the true performance of students.

\section{Interview}

The interviews were mainly used as a secondary source of information in order to confirm what the students had produced in the argumentative essays. The interview was used more as "a medium for guided reflections" (Buckingham, 2008 , p. 5) in this study.

The interview questions (See Appendix 2) aimed at uncovering whether the students used myside bias in their writing. The interview was conducted in English as the participants had a good command over English. The interview lasted 7 to 15 minutes to keep it manageable. A total of 30 participants (15 Male, 15 Female) were randomly selected to take part in the interview.

\section{FINDINGS AND DisCUSSION}

This section provides us with a report and a discussion regarding the research findings in response to the research question.

\section{A. Argumentative Writing Task}

The argumentative writing tasks were the essence of the present study. In the final stage SPSS was employed to obtain the results and also the inter rater reliability. In order to be objective in presenting the results of the study, it was essential that more than one rater analyze the essays (Connor, 1996). Cohen's Kappa was calculated (See Table 1.) for myside bias in order to report the inter rater reliability.

TABLE 1.

KAPPA INTER RATER RELIABILITY RESULT FOR MYSIDE BIAS

\begin{tabular}{|ll|l|l|l|l|}
\hline & & Value & Asymp. Std. Error(a) & Approx. T(b) & Approx. Sig. \\
\hline $\begin{array}{l}\text { Measure of Agreement } \\
\text { N of Valid Cases }\end{array}$ & Kappa & .900 & .049 & 8.058 & .000 \\
\hline \multicolumn{7}{|c|}{ a Not assuming the null hypothesis. } \\
\hline
\end{tabular}

b Using the asymptotic standard error assuming the null hypothesis.

As one of the pioneering works on Kappa-type statistics, Landis and Koch (1977) successfully categorized the various ranges of Kappa statistics results according to their strength of agreement.

TABLE 2.

CATEGORIZATION OF KAPPA STATISTICS RESULTS ACCORDING TO STRENGTH OF AGREEMENT (ADOPTED FROM LANDIS AND KOCH, 1977, P. 165)

\begin{tabular}{|l|l|}
\hline \multicolumn{2}{|c|}{ (ADOPTED FROM LANDIS AND KOCH, 1977, P. 165) } \\
\hline$<\mathbf{0 . 0 0}$ & Strength of Agreement \\
\hline $\mathbf{0 . 0 0 - 0 . 2 0}$ & Poor \\
\hline $\mathbf{0 . 2 1 - 0 . 4 0}$ & Slight \\
\hline $\mathbf{0 . 4 1 - 0 . 6 0}$ & Fair \\
\hline $\mathbf{0 . 6 1 - 0 . 8 0}$ & Moderate \\
\hline $\mathbf{0 . 8 1 - 1 . 0 0}$ & Substantial \\
\hline
\end{tabular}

According to this categorization, the overall inter rater reliability (0.90) shows that the agreement between the two raters was "almost perfect" in this study.

1. English Essays

1.1. Myside Bias Feature 
This feature was present in order to check whether the participants paid attention to both sides of the argument in the argumentative essays or whether they just focused on proving their own point of views. The results are as follows (Table 3).

TABLE 3.

FREQUENCY RESULTS FOR MYSIDE BIAS FEATURE (ENGLISH ESSAYS)

\begin{tabular}{|ll|l|l|l|l|}
\hline & Frequency & Percent & Valid Percent & Cumulative Percent \\
\hline Valid & Yes (Myside bias present) & 44 & 55.0 & 55.0 & 55.0 \\
& No & 36 & 45.0 & 45.0 & 100.0 \\
& Total & 80 & 100.0 & 100.0 & \\
\hline
\end{tabular}

The results obtained from the essays and the interviews all pointed to the participants' desire to focus and prove their point of views. Many interviewees also referred to their support of myside bias in their writing. When asked about whether they paid attention to both sides of an argument in their argumentative writing, interviewee 27 maintained: "Most of the time I write what I think and sometimes what I think about something is more important than what people think".

\subsection{Myside bias and Gender}

The comparison between males and females (gender as independent variable) in regards to their use of myside bias in writing (dependent variable) showed that there is no significant difference in this regard $(\mathrm{t}=0.766, \mathrm{P}>.05)$. This was also what Stanovich and West (2007) reported.

TABLE 4.

THE RESULTS OF T-TEST FOR GENDER AND THE MYSIDE BIAS

\begin{tabular}{|c|c|c|c|c|c|c|c|c|c|c|}
\hline & & \multicolumn{2}{|c|}{$\begin{array}{l}\text { Levene's Test for } \\
\text { Equality of } \\
\text { Variances } \\
\end{array}$} & \multicolumn{7}{|c|}{ t-test for Equality of Means } \\
\hline & & \multirow[t]{2}{*}{$\mathrm{F}$} & \multirow[t]{2}{*}{ Sig. } & \multirow[t]{2}{*}{$\mathrm{t}$} & \multirow[t]{2}{*}{ df } & \multirow{2}{*}{$\begin{array}{l}\text { Sig. (2- } \\
\text { tailed) }\end{array}$} & \multirow{2}{*}{$\begin{array}{l}\text { Mean } \\
\text { Difference }\end{array}$} & \multirow{2}{*}{$\begin{array}{l}\text { Std. Error } \\
\text { Difference }\end{array}$} & \multicolumn{2}{|c|}{$\begin{array}{l}95 \% \text { Confidence Interval } \\
\text { of the Difference }\end{array}$} \\
\hline & & & & & & & & & Lower & Upper \\
\hline $\begin{array}{l}\text { Degree of } \\
\text { Home Culture } \\
\text { Attachment }\end{array}$ & $\begin{array}{l}\text { Equal variances } \\
\text { assumed }\end{array}$ & 0.277 & 0.602 & 0.766 & 38 & 0.448 & 0.13 & 0.171 & -0.215 & 0.477 \\
\hline
\end{tabular}

This in turn means that no relationship was found between the gender of the participants and the presence of myside bias in their English writings.

\subsection{Myside bias and Age}

Here, initially the participants' ages were divided into three pairs. These three age pairs included pair one: 20-26 year- old participants, pair two: 27-33 year-old participants, and pair three: 34-40 year-old participants. To determine whether there was a significant relationship between age and the myside bias a One-way ANOVA was run. The results from the One-way ANOVA illustrated that the findings were not statistically significant (Table 5).

TABLE 5.

THE RESULTS OF ONE-WAY ANOVA FOR AGE PAIRS AND MYSIDE BIAS

\begin{tabular}{|c|c|c|c|c|c|}
\hline & Sum of Squares & $\mathrm{df}$ & Mean Square & $\mathrm{F}$ & Sig. \\
\hline $\begin{array}{l}\text { Between Groups } \\
\text { Within Groups } \\
\text { Total }\end{array}$ & $\begin{array}{l}.026 \\
9.874 \\
9.900\end{array}$ & $\begin{array}{l}2 \\
77 \\
79\end{array}$ & $\begin{array}{l}.013 \\
.267\end{array}$ & .049 & .952 \\
\hline
\end{tabular}

According to the above table, no specific age group was specifically more biased towards proving their own point of view in the English argumentative writings.

\section{Persian Essays}

\subsection{Myside Bias Feature}

The result can be seen in Table 6 .

TABLE 6.

FREQUENCY RESULTS FOR MYSIDE BIAS FEATURE (PERSIAN ESSAYS)

\begin{tabular}{|ll|l|l|l|l|}
\hline & Frequency & Percent & Valid Percent & Cumulative Percent \\
\hline Valid & Yes & 30 & 37.5 & 37.5 & 37.5 \\
& No (Myside bias) & 50 & 62.5 & 62.5 & 100.0 \\
& Total & 80 & 100.0 & 100.0 & \\
\hline
\end{tabular}

The results obtained from the essays show that $62.5 \%$ of the Higher-intermediate Iranian EFL students paid attention to both sides of the argument and were therefore more objective when they wrote their Persian essays. One reason for this might be the participants' overall better command over their mother tongue as compared to the foreign language (English) which in turn assists them in focusing on both sides of the argument. 


\subsection{Myside bias and Gender}

The comparison between males and females in regards to their use of myside bias showed that there is no significant difference in this regard $(\mathrm{t}=0.597, \mathrm{P}>.05)$.

TABLE 7.

THE RESULTS OF T-TEST FOR GENDER AND THE MYSIDE BIAS

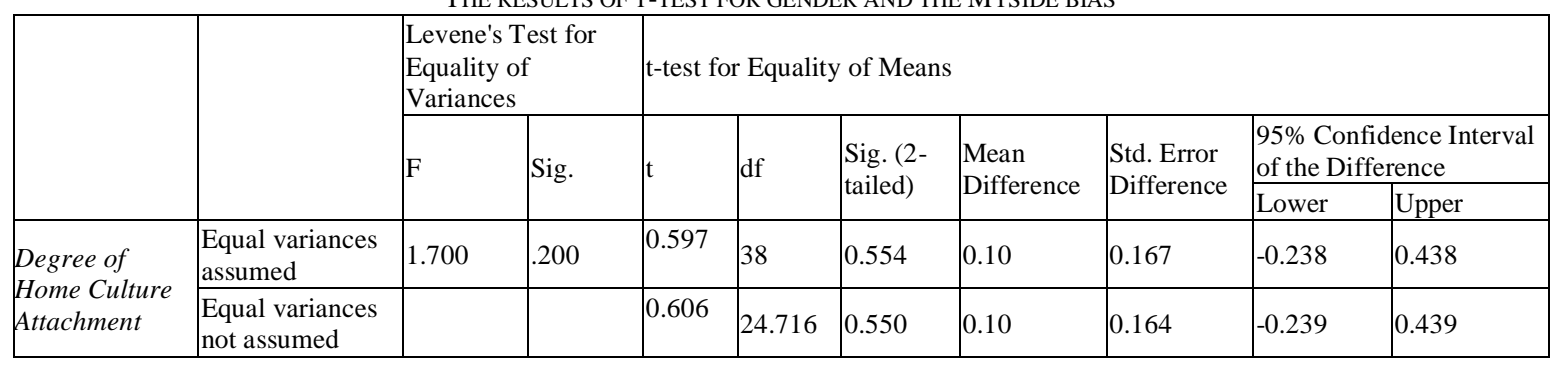

This means that no relationship was found between the gender of the participants and the presence of myside bias in their Persian writings.

\subsection{Myside bias and Age}

In this phase, the ages were grouped similar to the English essays. To determine whether there was a significant relationship between age and the myside bias, a One-way ANOVA was run. The results from the One-way ANOVA illustrated that the findings were not statistically significant (Table 8).

TABLE 8.

THE RESULTS OF ONE-WAY ANOVA FOR AGE PAIRS AND DEGREE OF HOME CULTURE ATTACHMENT

\begin{tabular}{|l|l|l|l|l|l|}
\hline & Sum of Squares & df & Mean Square & F & Sig. \\
\hline Between Groups & .496 & 2 & .248 & 1.033 & .366 \\
Within Groups & 8.879 & 77 & .240 & & \\
Total & 9.375 & 79 & & & \\
\hline
\end{tabular}

According to the above table, no difference was found among the age groups present in the study regarding the presence of myside bias.

\section{B. Comparison and Contrast between Participants' English and Persian Argumentative Essays}

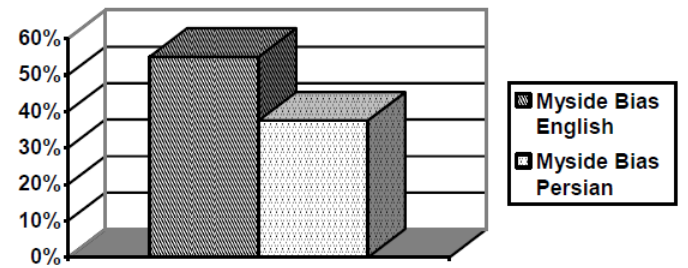

Figure 1. Percentage of English Myside Bias Vs. Persian Myside Bias

Myside bias -the author's failure to present the other side of the argument in an argumentative essay- was observed numerously in the Higher-intermediate Iranian EFL students written argumentative essays. According to Figure 1, the presence of myside bias was felt more in the English argumentative essays (55\%). The Persian argumentative essays only showed $37.5 \%$ for the presence of myside bias. This means that the Higher-intermediate Iranian EFL students in this study focused more on being objective when writing their Persian argumentative essays.

\section{Interview}

Although the information obtained through interviews is considered to be subjective in nature and can at best show certain aspects and experiences of each individual, "it nevertheless sheds light on what is usually a long-term, private process of skill development" (Buckingham, 2008). Each interview was confidential and it was conducted on an individual basis.

Through using the first interview question (have you been formally taught argumentative writing?), it was determined that none of the Higher-intermediate Iranian EFL interviewees had received any formal training in argumentative writing. In order to have more authentic essays and avoid formulaic writing, the researcher decided to base her study on the Higher-intermediate Iranian EFL students who had not yet at this stage received the English argumentative writing framework in their English classes.

Interview question 2 was related to myside bias (Do you concentrate on both sides of an argument or do you just address your point of view in argumentative writing? Why?). About $63 \%$ of the interviewees pointed out they only paid attention to their own point of view when writing. After hearing this from the interviewees, the researcher decided to ask them why they believed this to be true. Here are the most common replies. 
When I recognize what I think is more important, but sometimes it is very important and maybe somebody doesn't realize that (Interviewee 7).

My idea is more important than that of others (interviewee 18).

I just address at on my point of view because in that time, I believe in it (interviewee 26).

As for the other $37 \%$, they also had their own ideas on why they should consider both sides of the argument.

I think (eh) when for example we say (eh) we write, (um) we write an argumentative writing we should be fair and (eh) we should (eh) mention something which might be against what we think (eh), but (eh) and I try to concentrate on both sides (Interviewee 1).

Because (eh) if it's just (eh) I don't want to be a stubborn person and try to pay attention to the both sides of the argument and (eh), for example (eh) take up reasonable, rational idea and then (eh) choose my (eh) for example final decide (Interviewee 24).

Interview questions 3 (Do you believe that the English and Persian argumentative styles of writing are the same?) showed that although 55\% of the interviewees believed that Persian and English argumentative styles were different, they could not elaborate on how the two differed from one another.

The last interview question (Do you think it is necessary to formulate counter arguments in English argumentative writing?) shed light on the gravity of the problem. In this part, $83 \%$ of the interviewees declared that it was indeed unnecessary to formulate counter arguments and that their perspective regarding the argument only needed to be focused on.

\section{CONCLUSION AND SUGGESTIONS}

The results of this study can influence EFL students, EFL teachers, and syllabus designers. It can help EFL students realize that they need to write more objectively in English; and this in turn can aid them to write closer to the standards required by international conventions and the academic community. The results can also encourage awareness raising among the EFL teachers to include pointers on avoiding myside bias by their EFL students. According to Barron (1995) it is important to teach the students that "typically, no single argument is decisive, and we must consider the total weight of evidence and the possibility of even stronger arguments on the other side (p.3).

The students need to be directly taught that the presence of myside bias in their writings can bring about several problems. Toplak and Stanovich (2003) believe that the presence of myside bias has a negative relationship with rational thinking. This means the less the presence of myside in an argumentative task, the more rational the result would be evaluated by the reader. Students need to be made aware that by bringing counter arguments into their writings they can create a more favorable impression of themselves and increase their credibility in the eyes of the readers (Wolfe \& Britt, 2008). Also they can "minimize the impact of other side points by framing them in the best possible light" (Wolfe \& Britt, 2008; p. 2). In addition to the above, by including counterarguments into an argumentative text, the writer can assist the reader since through this "readers are less likely to expend additional cognitive effort themselves generating counterarguments" (Wolfe, Britt, Butler, 2009; p. 188).

It is very important to keep in mind that the instructions on myside bias need to be given directly to the students and that passive teaching can not be effective. As Wolfe, Britt and Butler (2009) found while initially 50\% of the undergraduate research students they studied did not make any references to the other side, after reviewing a booklet on the importance of referring to arguments on both sides of an issue found that still $33 \%$ of these participants exhibited myside bias in their work. For example using pre-writing worksheets for students going through the steps one by one can be of great assistance to the students. The pre-writing worksheets are designed to plan the key parts of the students' essays. Wolfe, Britt and Butler (2009) found that by using such worksheets the students paid more attention to including counterarguments in their argumentative writings. In fact, while only $60 \%$ of their control group mentioned counterarguments, $90 \%$ the tutorial group focused on them. This shows how effective the use of pre-writing worksheets can be.

The results from the present study can assist syllabus designers to generate some guidelines for EFL programs used for teaching Iranian students. Syllabus designers can use the results to make possible changes to the already existing syllabuses for English language textbooks taught at language institutes. They can try to add some pointers that help EFL students become aware of the presence of myside bias and its harmful effect on their composition. It is with the collaboration of teachers and syllabus designers that the students can be made aware of the harmful effects of myside bias in their writing.

\section{APPENDIX1. PARTICIPANTS’ DEMOGRAPHIC}

Part 1: Please fill in the background information section below.

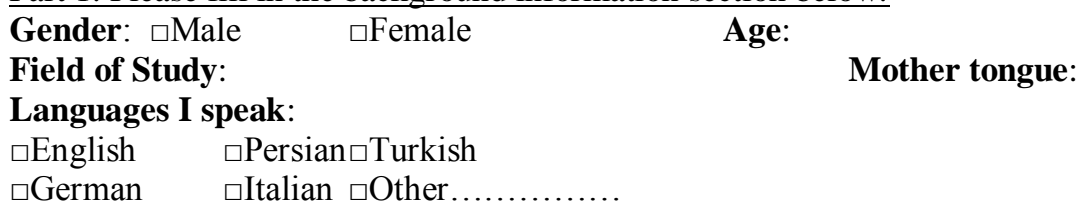




\section{How long have you studied English? \\ Have you lived abroad? \\ $\square$ Yes.

(If you answered yes, where and how long?)

\section{Academic qualifications:}
$\square$ Diploma
$\square$ Master or Master student
$\square$ Bachelor or Bachelor student
$\square \mathrm{PhD}$ or PhD student

Have you had formal training in English writing (such as report writing, essay writing, formal letter writing,...)?

$\square$ Yes.............. $\square$ No

(If you answered yes, where and how long?)

\section{APPENDIX2. INTERVIEW QUESTIONS}

1. Have you been formally taught argumentative writing?

2. Do you concentrate on both sides of an argument or do you just address your point of view in argumentative writing? Why?

3. Do you believe that the English and Persian argumentative styles of writing are the same?

4. Do you think it is necessary to formulate counter arguments in English argumentative writing?

\section{REFERENCES}

[1] Baron, J. (1995). Myside bias in thinking about abortion. Thinking and Reasoning, 1, 221-235.

[2] Buckingham, L. (2008). Development of English academic writing competence by Turkish scholars. International Journal of Doctoral Studies, 3, 1-18.

[3] Connor, U. (1996). Contrastive rhetoric: Cross cultural aspects of second-language writing (third ed.). Cambridge: Cambridge University Press.

[4] Creswell, J. W. (2009). Research design: Qualitative, quantitative, and mixed methods approaches. Thousand oaks, California: SAGE Publications, Inc.

[5] Eemeren, F. H. V., \& Houtlosser, P. (2005). Theoretical construction and argumentative reality: An analytic model of critical discussion and conventionalised types of argumentative activity. In D. Hitchcock \& D. Farr (Eds.), The uses of argument: proceedings of a conference at McMaster University (pp. 514): Ontario Society for the Study of Argumentation.

[6] Givi, H. A., Hakemi, E., Shokri, Y., \& Tabatabee, M. A. (2006). Persian language and writing (25 ed.). Tehran: SAMT Publications.

[7] Hinds, J. (1990). Inductive, deductive, and quasi-inductive: Expository writing in Japanese, Korean, Chinese, and Thai. In U. Connor \& A. M. Johns (Eds.), Coherence in writing: Research and pedagogical perspectives (pp. 87-110). Arlington, VA TESOL.

[8] Kachru, Y. (1999). Culture, context and writing. In E. Hinkel (Ed.), Culture in Second Language Teaching and Learning (pp. 75-89): Cambridge University Press.

[9] Kim, I.-H. (2008). Essays of Korean and American children following collaborative literature discussion. University of Illinois, Urbana, Illinois.

[10] Kobayashi, H., \& Rinnert, C. (2008). Task response and text construction across L1 and L2 writing. Journal of Second Language Writing, 17, 7-29.

[11] Landis, J. R., \& Koch, G. G. (1977). The measurement of observer agreement for categorical data. Biometrics, 33(1), $159-174$.

[12] Liebman, J. D. (1992). Toward a new contrastive rhetoric: Differences between Arabic and Japanese rhetorical instruction. Journal of Second Language Writing, 1, 141-165.

[13] Liu, Y., \& You, X. (2008). Negotiating into academic discourses: Taiwanese and U.S. college students in research writing. International Journal of English Studies, 8(2), 152-172.

[14] Macpherson, R., \& Stanovich, K. E. (2007). Cognitive ability, thinking dispositions, and instructional set as predictors of critical thinking. Learning and Individual Differences, 17, 115-127.

[15] Mason, N., \& Otte, G. (1994). Writers' roles: enactments of the process: Harcourt Brace College Publishers.

[16] Nussbaum, E. M., \& Kardash, C. M. (2005). The effects of goal instructions and text on the generation of counterarguments during writing. Journal of Educational Psychology, 97, 157-169.

[17] Oi, K. (1984). Cross-cultural differences in rhetorical patterning: A study of Japanese and English. JACET Bulletin 17, $23-48$.

[18] Oi, K., \& Kamimura, T. (1995). A pedagogical application of research in contrastive rhetoric. Paper presented at the annual TESOL Conference.

[19] Oliver, R. T. (1971). Communication and culture in ancient India and China. Syracuse, NY: Syracuse University Press.

[20] Petric, B. (2005). Contrastive rhetoric in the writing classroom: a case study. English for Specific Purposes, 24, $213-228$.

[21] Raimes, A. (1983). Techniques in teaching writing. Oxford: Oxford University Press.

[22] Reid, J. M. (1984). ESL composition: The linear product of American thought. College Composition and Communication, $35(4), 449-452$.

[23] Rozakis, L. E. (2000). Why writing matters Complete idiot's guide to writing well (pp. 3-14): Penguin Group (USA) Incorporated.

[24] Sadighi, F., \& Maghsudi, N. (2000). The relationship between motivation and English proficiency among Iranian EFL learners. Indian journal of applied linguistics, 26(1), 39-52. 
[25] Saneh, N. A. (2009). Intercultural rhetoric in higher education: The case of Iranian students' textual practices in North American graduate schools. University of Ottawa, Ottawa.

[26] Stanovich, K. E., \& West, R. F. (2007). Natural myside bias is independent of cognitive ability. Thinking and Reasoning, 13(3), 225-247.

[27] Toplak, M. E., \& Stanovich, K. E. (2003). Associations between myside bias on an informal reasoning task and amount of postsecondary education. Applied Cognitive Psychology, 17, 851-860.

[28] Vaezi, Z. (2009). Language learning motivation among Iranian undergraduate students Iranian Journal of Language Studies, $3(1), 79-104$.

[29] Villasenor, J. A. (2003). Contrastive rhetoric and standardized writing assessment: the experiences of non-native speakers of English in a secondary setting. Kent State University, Ohio.

[30] Wolfe, C. R., \& Britt, M. A. (2008). The locus of the myside bias in written argumentation. Thinking and Reasoning, 14(1), 127.

[31] Wolfe, C. R., Britt, M. A., \& Butler, J. A. (2009). Argumentation schema and the myside bias in written argumentation. Written Communication, 26(2), 183-209.

[32] Zia Houseini, S. M., \& Derakhshan, K. (2006). Transfer of first language of foreign language writing: A contrastive rhetoric study of English and Farsi. Quarterly Journal of Humanities Al-Zahra University, 16(58), 75-91.

Atiyeh Kamyabi Gol was born in 1983. She is an assistant professor at the Faculty of Letters and Humanities, Ferdowsi University of Mashhad, Iran. She received her PhD degree in Applied Linguistics from University of Malaya, Malaysia in 2012. She received her M.A. degree in English language teaching from Ferdowsi University of Mashhad, Mashhad, Iran in 2009, and she also got the B.A. degree in English language and literature from Ferdowsi University of Mashhad, Mashhad, Iran in 2006. Her areas of research include Second language writing, Applied linguistics, Cultural aspects of EFL, Perceived culture, Anxiety in EFL learning, Self disclosure in EFL teaching and learning. She has published in the areas of Cultural Attachment and Accent Mimicry and also Home Culture Attachment, Self-Regulation and Job Performance, Contrastive Rhetoric. 